\title{
The Racial, Ethnic, and Social Class Achievement Gaps:
}

\section{A Systems Analysis}

\author{
Alan Kibbe Gaynor \\ Boston University School of Education \\ 2 Silber Way, Boston, Massachusetts 02215, USA \\ Tel: 1-617-721-5581Ｅ-mail: agaynor@bu.edu
}

Received: July 29, 2011 Accepted: August 15, $2011 \quad$ Published: February 1, 2012

doi:10.5539/ies.v5n1p28 URL: http://dx.doi.org/10.5539/ies.v5n1p28

\begin{abstract}
This system dynamics analysis draws on the literature to outline the factors commonly discussed as predictive of and, perhaps, causally related to problematic differences in academic achievement among students who vary in race, ethnicity, and social class. It first treats these as a wide-ranging set of exogenous variables, many of which interact with each other, all of which influence academic achievement. "Causal-Influence Diagrams" are drawn to show these complex interactions. Then a distinction is drawn among the "traditional" school, the "gap-closing" school, and the "exceptional" school.

In a subsequent section of the paper, variables that are not a part of the internal institutional system of schooling are mostly stripped away. In this section, a typology is presented and a distinction is drawn between two generic types of schools in contrast to what might be called the "traditional" school: the "gap-closing" school and the "exceptional" school.
\end{abstract}

Keywords: Achievement gap, School reform, School improvement

\section{Introduction}

\subsection{The Problem}

The long-documented differences in academic achievement between low-income, African American, and Latino students in general, on the one hand, and more affluent students of European and Asian origins, on the other hand, are important both because they undermine American economic productivity and because they challenge, in the long term, the cohesion and stability of the American social order.

\subsection{A Systems Analytic Theory of the Problem}

There is an extensive literature on these racial, ethnic, and social class achievement gaps in the United States (see, in particular, Miller, 1995; Jencks \& Phillips, 1998; Kober, 2001; McKenzie \& Company, 2009; Murphy, 2010). In this paper I present a tentative theory of the systemic interconnections among the variety of predictive and causal factors of these achievement gaps identified in that literature. I say "tentative" because, while a great deal of work has been done in identifying and assessing the relationship of individual factors to student academic achievement, little is known of the interactions among them and close to nothing is known with empirical certainty about the reciprocal causal effects of what, in fact, is a multitude of variables. For well-known and good reasons, only a small fraction of the studies reported in the literature are experimental. The vast majority of the claims that are made about the relationship of various factors to academic achievement are predictive, not demonstrably causal. In my judgment, in most cases the relationships are indirect and interactive, involving various confounding variables. Many of the studies are entirely or substantially qualitative in any case.

There is an old saying in ecological studies that "you can't do one thing at a time." My reading of the literature on the achievement gaps convinces me that the same is true in the field of education, particularly with reference to closing these achievement gaps. It is useful to focus - as is common in the literature - on particular factors such as teacher quality, early childhood education, resilience, parenting practices, language development, and school leadership. However, it is important to note that despite some fluctuations over decades, and despite some relatively isolated case examples to the contrary, racial, ethnic, and social class achievement gaps have proven to be stubborn and lasting. 
I believe that there remains - as a basis for truly informed policy formulation - a pressing need to put this collection of individual factors together into a systemic whole. I take the position in this essay that only on the basis of a holistic, dynamic, interactive understanding of what might be called the "achievement-gap problem system" can reasonable policy choices be formulated and assessed. I would add, as I comment later, that problem systems analysis also provides critical insights into the state of the relevant knowledge base and the remaining research requirements with respect to the focal problem.

My triple intent is simple. First, I want to suggest substantively a theory of the achievement-gap problem that is open for discussion and that may, in the longer term, provide a basis for identifying and assessing better policies to close the achievement gaps. Second, I want to illustrate a way of thinking at the policy level that I believe can have great value not only in relation to this problem, but also in addressing a wide range of policy problems. Finally, I want to move the analysis, in the final section of this paper, from a consideration of the factors that are of immense importance in determining fetal and early childhood development but which, for the most part, are not under the control of school personnel to a focus on the nature of schooling as a complex of interactions that can be seen in terms of intermediary structures - called positive and negative feedback loops. An awareness of these intermediary structures encourages and facilitates a conceptual understanding of the dynamics of school effectiveness, student achievement, and the dynamics of stability and change in school systems. This awareness provides a foundation for thinking about policy options in a systematic way, policy options that constitute the basic tools of school leadership.

\subsection{The Importance of the Big Picture}

Clearly, there are no guarantees. However, I believe strongly that it is important to do everything we can to see the "big picture" and I am writing this essay to illustrate an approach to seeing the big picture related to the systemic causes of these achievement gaps. However, it is important to note that this effort represents only the first stage of a long-term, multi-stage piece of work. It is also important to understand that at this point in time - given the thinness of our knowledge of specific relationships and effect sizes among the causal factors - there remain very significant epistemological problems in achieving a credible big-picture model of the achievement-gap problem system. (Note 1)

In this paper, I draw on the literature to outline the factors commonly discussed as predictive of and, perhaps, causally related to these problematic differences in academic achievement. I then hypothesize a range of causal interactions among these factors. I illustrate the theorized relationships in a series of "sector diagrams" keyed to the outline, each of which I explain narratively in the following text. (Note 2) These sector diagrams theorize causal influences within each of the sectors, but they also suggest and represent causal influences across sectors.

\section{Epistemological Issues}

\subsection{Causal Influence Diagrams}

It is important to emphasize that it is precisely here that key epistemological issues become apparent. I represent the causal relationships in the diagrams in the form of arrows. I place a plus or minus sign at the head of each arrow to indicate whether the hypothesized effect of the first variable on the second is positive (i.e., in the same direction, like a positive correlation) or negative (i.e., in the opposite direction, like a negative correlation). This is all well and good but how do I know that these variables are causally related in this way? I am drawing on the literature review to which I referred at the outset of this essay (and which is represented in the bibliography at the end of the paper). The "causal influence" diagrams are based on my reading of this literature. However, in the last analysis, what I am presenting is entirely theoretical. The theory delineates my (fundamentally qualitative) understanding and interpretation of the literature. The diagrams, collectively, represent my tentative "theory of the problem" of differential student achievement in school.

I hope that as you examine them, you find them credible. I also hope that they illustrate for you what I mean by a "systems approach" to policy analysis. After all, while one of my motivations for writing this piece is to share how I think about the achievement-gap problem in particular, a second motivation is to illustrate for you a mode of thinking that I believe can serve educational policy formulation in general.

To this point in the essay, in the tradition of an "introduction," I have spoken broadly about the systems approach to policy analysis. I do recognize, however, that while there may be some exceptions, most of you will probably find my diagrams rather like "spaghetti"-lacking in "immediate intelligibility." Therefore, I list the hypothesized variables and relationships up front and, also, I do the best I can to explain in each case - in an accompanying narrative text-what meaning I am trying to convey in that diagram about the factors, and their interactions, that have helped maintain the significant differences in academic achievement over time between students of different racial, ethnic, and social-class origins. I keep these narrative explanations brief, although the length and density of 
these explanations necessarily vary with the scope and complexity of the sectors. (Note 3)

\subsection{Units of Measure}

This explanation of the ultimate specification of the model mathematically leads me to discuss another kind of epistemological issue that is worth talking about. It turns out, given the current state of knowledge, that some variables can be quantified in "real" physical units of measure whereas the metrics for others are "dimensionless" units, keyed to an arbitrary scale. So, for example, height and income are measured in physical units (inches and dollars). Even IQ or achievement scores are "real" in the sense of objectively reflecting test performance.

As far as I know, though, one has to represent differences in "aspiration" or "motivation," for example, on dimensionless scales of one-to-ten or one-to-a-hundred (unless there are some physical or "objective" test metrics of these variables of which I am unaware). Anxiety, in this sense, was similar to aspiration and motivation until it was physically measured in terms of Galvanic Skin Response - or stress in terms of indicators such as cortisol and epinephrine. So one of the issues for an analyst seeking to translate a purely conceptual model—such as those presented in this essay - into a mathematical model is to determine the units of measure for each of the variables comprising the model. In each case, the analyst must determine whether a variable's metric is a physically grounded objective unit of measure or a more conceptual, dimensionless, measure.

Clearly, it is far more precise and persuasive to quantify variables in a theoretical model in physical rather than dimensionless units; however, this is not always possible. What is evident here is another epistemological issue that limits the power of an analytic model. So, in the end, these models are useful in describing theories of problems in a mode of description that is greatly more precise than words, alone. Also, when they are put into mathematical form, these models can be made to "simulate" the behavior of problem systems over time (which is why they are called "dynamic" models, dynamic referring to changes over time), to provide increased understanding of how the problem system "works" to produce the problem, and how different policies might work—or not— to ameliorate the problem, or make it worse, given the theoretical assumptions of cause and effect built into the model, and given the time frames of causal effect (which must also, ultimately, be built into the model). Once these simulations are "run," they can be validated in relation to historically documented system behaviors, and particular causal connections that are centrally embedded in key causal systems can, if possible, be approached experimentally (Parker, Ian, 2010).

\subsection{Pros and Cons of Complexity Modeling}

So, you can see that there are a lot of knowledge issues that are exposed explicitly in the course of modeling dynamic problem systems, such as the achievement-gap problem system. One can view these issues in a positive or negative light. Positively speaking, the very construction of a policy model makes conscious what assumptions are based on solid knowledge and where further research — or better research—is needed. It raises explicitly issues of where physical units of measure are known, or not, and the extent to which hard data are or are not available. And it also forces attention to assumptions about "time frame of effect" and how information delays and effect delays affect the problem and policies to influence it. (Note 4)

Or, I suppose, one can reject the fundamental value of such an exercise, presumably in favor of simple words or, alternatively, regression analyses. In my view, words alone carry all of the epistemological baggage that I have identified with coherent systems analysis, but more so. Regression analysis has proven historically to be clearly valuable. Its great limitation is that its findings are predictive, not causal, and that it is open to serious epistemological flaws of its own, especially those related to unspecified-possibly confounding — variables. Also, multiple regression analysis reflects, at root, an additive, not a systemically interactive theoretical perspective, despite the occasional inclusion of "interaction" terms.

Let me reiterate what I stated at the outset, that this is a long-term project. While much is known and much has been written about the achievement-gap problem by a great many dedicated and talented researchers, I find myself at the beginning of trying to "pull it all together." The achievement gap problem seems so complex, composed of so many variables, embedded in individuals, schools, families, communities, and the society as a whole that an assessment recently made of the decades-long decline of the newspaper industry seems apt, "There really is no single cause. Rather you could pick any single cause, and that on its own would be enough to explain the problems - except it's not on its own." (Josh Cohen, as reported by James Fallows, The Atlantic, June 10, 2010, p. 46).

In some ways this reminds me of the challenge of deriving effective medical interventions from the Genome Project. Scientists seeking to move from the basic science of the Genome Project to gene-based medical treatments talk of the multi-gene (i.e., multivariate) basis of disease and the difficult challenge of finding the "pathways" from basic to the applied science of medical and pharmaceutical intervention. Analogously, in education we are faced with the challenge of finding the "pathways" from an understanding of the multivariate causes of academic achievement (e.g., 
factors associated with poverty, health, culture, family demographics, parenting practices, community variables, early education and schooling, including curriculum, instructional practices, and teacher quality, and the neurological and environmental interactions of brain development, including fetal brain development) to "treatments" for significant differences in academic achievement tied to social class, ethnicity, and race.

The diagrams put forward in this essay describe what I believe to be important variables and, at least hypothetically, causal relationships among them that are suggested in the literature. However, I make no effort at this stage of the work to deal with issues of metrics, time delays, and effect sizes. Rather, I recognize that this theory of differential academic and life achievement is deeply layered, revealing complex causal interactions that can be described in general terms at one level, but that can be fully specified only by distinguishing and particularizing the associated metrics, time delays, and effect sizes at a more concrete sub-level.

\section{A Macro-Theoretical Layer}

\subsection{A Distributional Theory of Life Chances}

While in this essay I describe a holistic theory of school achievement-portraying in interaction many factors that contribute to any individual student's rate of growth in learning, and thereby providing a broad understanding of why it is that one student's rate of learning is different from that of others - perhaps systematically related to culture and to the objective realities of race, ethnicity, wealth, and poverty, underlying this broad theory is a still more fundamental theoretical perspective. I call this underlying conceptual framework the "Probability Distribution Theory of Life Chances."

I believe that each of us "swims" or "surfs" through an almost infinite number of "probability distributions" representing the relative likelihood that diverse external realities will intrude upon and influence our lives-some genetic, some environmental, some good, some bad. These possibilities have varying levels of probability; some are extremely unlikely. These are the so-called "black swan" events, the probability of which would be many standard deviations out on a normal curve but which — collectively — are much more likely to occur (Taleb, 2010; Taleb, 2004). The point here is that it is much more likely that some highly improbable event will occur than it is that any particular one of these "black swan" events will occur. Other, more normal, events are substantially more likely to occur, with varying degrees of probability.

How one reacts to any combination of these possibilities is open to a variety of personal characteristics and circumstances, such as will, resilience, perseverance, physical and cognitive capacities, and available resources - each of which, however, is, itself, likely shaped by other chance events, genetic, familial, and cultural, for example. As years of research suggest, many likely negative probabilities that affect school and life achievement are associated with poverty and culture (including race and ethnicity). Key probabilities related to school and life include health, nutrition, different types of mentoring and opportunity (Gladwell, 2008), and the development of language, patterns of thought, social capital, motivation, aspiration, resilience, even the neurology of the brain, itself, which the latest research informs us is characterized by great plasticity-especially at young ages - and by evolutionary interaction with environment (Caldwell, 1998; Gopnik, Meltzoff, and Kuhl, 1999; Kotulak, 1997; Schiller, 1997; Shore, 1997; Siegel, 1999; Wexler, 2006).

My point is that both the systemically correlated events that commonly separate children — and ultimately adults—in terms of school and life achievement and the "black swan" events that seem more like "chance determinism" can play important roles in the development of human beings and, therefore, constitute the necessary subject matter of schools and educational policy. In fact, these two types of probabilistic events, I would argue, affect each other interactively. The result is that while quite unexpected positive (i.e., "opportunities") and negative (i.e., "crises") events can happen to any person, young or old, those who already possess greater knowledge, skills, and social and financial capital, and who have higher levels of motivation, aspiration, and resilience, have a systematically greater probability of encountering positive "black swan" events, and a greater capacity to take advantage of them, while the reverse is true for those with lesser knowledge, skills, and social and financial capital, and who have lower levels of motivation, aspiration, and resilience (Gladwell, 2008).

\subsection{The Stochastic Environment of Schools}

I also take the position, in the third section of this paper, that schools, themselves, and the communities in which they find themselves, are significantly products of chance. As I have thought at length about why and how schools respond differently to students with differential developmental trajectories and who are situated in different family, peer, and community environments, which are simply "givens" when children come to school, I have concluded that - beyond community wealth and average level of education, which are not variables that are easy to change, or that are likely to change in any brief interval of time-leadership is a pivotal factor in determining the longitudinal 
quality of schools.

As I mentioned earlier in this essay, community leadership has a powerful influence on the quality of school leadership - which, in turn, exercises determinative influence on teacher quality, curriculum, policies related to pedagogical practices for individual students, parent and community relations, community support for schools, that is, on all the dimensions of schooling. It is with respect to community and school leadership, in my view, that chance plays what may be an unsatisfyingly determinative role.

In this paper, I focus on the organizational and pedagogical options (tools) available to leadership. It may be that the effects of "chance" can be moderated in the future by advances in science, by a greater understanding, for example, of the origins and dynamics of school and community leadership as well as of fetal and early childhood development, parenting practices, and the cultural interfaces among race, ethnicity, family, and wealth and poverty that affect not only children but also the schools, as institutions, that serve them well or badly.

The point I would like to highlight in framing this essay is that each of the factors I have put forward as a component of the achievement-gap problem system can itself be viewed as influenced developmentally in a child's life by a range of probability-based events and conditions that cohere in making the child what he or she is as a student in school and later in the rest of his or her life - and also that schools, themselves, and the communities they serve, are products of stochastic processes and events that are hard to predict or understand.

\subsection{So What, Then, Is the Role of the School?}

It looks to me as if one should view the school—itself a largely probabilistically determined institution, determined by chance related to community, leadership, legal context, etc.- as charged by Society as a provider of opportunities for students, especially for those whose lives to that point have been poorly endowed with such opportunities, to enhance their aspirations and levels of motivation, their beliefs in themselves and their futures, opportunities that provide a systematic context in which they can gain knowledge, skills, a sense of self-efficacy in relation to socially important activities, and social capital in the form of cross-cultural networking.

In the end, then, after all the theorizing, we are faced as school people with the implications of whatever we come to believe we know about the genesis of individual and group variation in academic and life achievement for the following basic question: How then, given a growing understanding of the systemic complexities of student achievement, can schools learn to operate as "opportunity-givers," especially to children who have had to swim through some pretty negative "probability distributions" in terms of the external realities of their lives? (Note 5)

The ultimate goal of complexity modeling, once it is specified mathematically, is to be able to "run" the model, to simulate how this set of interactive theoretical assumptions would actually operate to produce school effects that could be examined historically - in terms of the macro-effects of the model but also in terms of its internal operation over simulated time. Such an examination supports an operational critique of the theoretical assumptions built into the model. It also supports the introduction of simulated policy interventions once the basic model seems essentially satisfactory, so that policy ideas can be tested virtually before they are enacted at high cost and high stakes in the real world.

\section{Model Sectors and Diagrams}

This composition of sectors - and factors within sectors - draws substantially on the work of Nancy Kober (2001) and Coby Meyers (Meyers, in Murphy, 2009). Each sector, or sub-sector, is followed by what is called by those in the field of System Dynamics, a "causal-influence" diagram.

\subsection{Student Sector (Note 6)}

Level of Aspiration

Level of Academic Motivation

Level of Resilience

Extent of Vocabulary

Reasoning Ability and Level of Critical Thinking

Willingness to Work and Self-discipline

SES Level of School Peers

Level of Academic Achievement (Note 7)

4.2 Home Sector (Note 8)

Relative Family Income (Constant) 
Mother's Education (Constant)

Race: Black, White, Asian, Other (Constant)

Language: English or Other (Constant)

Effect of Home Culture on Vocabulary Development

Effect of Home Culture on the Student's Aspiration and Academic Motivation

Emphasis on Reasoning in Communicating with Children in the Family

4.3 Community Sector (Note 9)

Median Community Income

Degree of Crime and Violence

Level of Support for Schools

School/Academic Orientation of Community Peer Group

Proportion of Children in Pre-School

Legacy of Discrimination

Level of Community Access to Pre- and Post-Natal Parent Training

\subsection{School Sector}

The school sector is divided into six interacting subsectors. These include the following: (A) School Demographic Subsector; (B) School Finances and Facilities Subsector; (C) School Academic Subsector; (D) School Assessment and Accountability Subsector; (E) School Parent Involvement Subsector; and (F) Instructional Time Subsector. The subdivision of the school sector is a testament to its importance as the primary locus of the problem, as a center of concern, as a focal point of policy interest, and to its complexity as a necessary agent in whatever attempts are made to close the academic achievement gaps.

However, it may be, at the point where the model is fully specified and mathematicized, and where it is used to run policy simulations, that students of "different backgrounds" will be "run through" the model from birth on and that, therefore, the school sectors will be "turned off" until each of the simulated students reaches school age and becomes part of the school community. However, from my perspective, all this lies in the future.

4.4.1 School Demographics (Note 10)

Median SES of the Student Population

Proportion Low-Income Students

Proportion Minority Students

4.5 School Finances and Facilities (Note 11)

Per Student Expenditure on Instruction

Per Student Expenditure on Instruction/ Median for District

Per Student Expenditure on Instruction/ Median for State

Per Student Expenditure on Instruction/ Median for Nation

Quality and Adequacy of School Plant

4.6 School Academics (Note 12)

Tracking: Yes/No

Emphasis on Rigorous Courses

Median Teacher Quality

Quality and Intensity (Note 13) of Instructional Leadership in the School

Level of Teacher Professional Development

School Involvement in Major Comprehensive School Reform: Yes/No

Median Class Size

Special Tutoring and Other Academic Support Services for Academically Challenged Students in the School or School District 
Median Percent Time on Task

Frequency and Intensity of Using Educational Research Data to Inform Curriculum and Teaching

4.7 Emphasis on Student Assessment and Teacher Accountability (Note 14)

Frequency of Collecting Individual Student Performance Data

Intensity of Using Individual Student Performance Data to Inform Instruction

Delays in Using Individual Student Performance Data to Inform Instruction

Frequency of Collecting General Performance Data Across Academic Courses

Intensity of Using General Performance Data for Teacher Development, Evaluation, and Curriculum Development

Delays in Using General Performance Data for Teacher Development, Evaluation, and Curriculum Development

\subsection{School Involvement with Parents (Note 15)}

Level of Parent Participation in School Activities

Level of Parent Involvement in School Governance

Level of School Involvement in Educating and Supporting Parents to Help the Academic Achievement of Their Children

4.9 Instructional Time (Note 16)

Length of School Day

Length of School Week

Length of School Year

\section{Section Summary and Conclusions}

In this section of the paper I make a case for moving beyond a focus on individual factors in trying to close the racial, ethnic, and social class achievement gaps. I illustrate a holistic approach to analyzing and describing the nature of what I called the achievement gap problem system. Drawing on a review of the literature represented by the bibliography included in the appendix to this essay, I describe this problem system in terms of four sectors - the Student Sector, the Home Sector, the Community Sector, and the School Sector.

Because of its centrality and complexity, I describe the school sector in terms of six subsectors: the School Demographic Subsector, the School Finances and Facilities Subsector, the School Academic Subsector (the pivotal and most complex subsector in terms of potential intervention to make a difference) (Note 17), the School Finances and Facilities Subsector, the School Assessment and Accountability Subsector, the School Parent Involvement Subsector, and the School Instructional Time Subsector. In addition, I explain narratively the dynamics portrayed in each of the sectors and subsectors, hopefully making the diagrams more conceptually digestible to a broad audience.

The next thing I found myself thinking more deeply about—which is the essence of dynamic systems analysis-is the presence of what are called, in systems parlance, positive and negative "feedback loops." While problem systems are, indeed, impacted by external factors (exogenous variables), what is crucially important in understanding these systems from a policy perspective is to identify the internal connections that determine how the system is able to respond to these external factors.

These include interactions among elements that maintain stability (Note 18) (what are called negative feedback loops) and those that amplify certain values in the system (what are called positive feedback loops). For example, in the course of my earlier explanation of the dynamics in the school academic sector I highlighted a set of relationships among student academic achievement, teacher expectations for student performance, the rigor of instruction for all students, and student academic motivation. In Figure 10, which cuts across sectors of the model, I pull out these variables and indicate their reciprocal causal-influence relationships in isolation from the rest of the model. (Note 19)

The diagram indicates that for students whose initial academic achievement is high, teacher expectations for the student's future performance will be high, also, leading the teacher to present more rigorous content to the student, with more intensive instructional and interpersonal engagement, further increasing the student's academic achievement. For a student with low initial academic achievement - as is typical of African-American, Latino, and poor students - teacher expectations for the student's future performance will be low, leading the teacher to present less rigorous content for the student to master, with less intensive instructional and interpersonal engagement, keeping the student's academic achievement low. 
You can see what the effect of these dynamics is: initially high-achieving (typically middle-class White and Asian) students are reinforced toward increasing academic achievement while the same dynamics reinforce initially low-achieving students in a downward direction (or at least serve to limit their rates of academic growth, thus increasing, maintaining, or limiting the closure of problematic achievement gaps). Such a differential effect is characteristic of positive feedback dynamics when applied to individuating initial conditions.

In the case of discriminatory teacher expectations, the effects are further exacerbated by two related dynamics, which are also reinforcing in the divisive manner described in the previous paragraph. These both involve the effects of teacher expectations on academic motivation and, in turn, on the student's level of academic achievement. The model hypothesizes that, causally, academic motivation tends to correlate positively-higher or lower-with changes in teacher expectations. At the same time student academic achievement and student academic motivation are self-reinforcing. Thus, this entire set of positive feedback loops has the practical effect of reinforcing either high or low initial levels of academic achievement. It seems reasonable, then, to see this structure, to the extent that it exists in schools, as contributing to the empirically-observed divergence in achievement over the course of schooling (K-12) between initially high and initially low achievers - that is, typically, related to racial, ethnic and social class differences.

The main point I want to make here is that such an analysis leads policy analysts and educators in general to think about how to intervene to modify such seemingly pernicious dynamics - for example, in this case to break the empirical link between observed student academic achievement and teacher expectations (Clauset, 1982; Clauset and Gaynor, 1982; Clauset and Gaynor, 1992), to substitute, at least for lower-achieving students, fixed standards of teacher expectations that are at least as high, for all students, as national levels of student academic achievement (see Figure 11) (Note 20). Figure 11 illustrates a "thermostat" loop where teacher expectations are keyed to national standards and where extra help for students is at its highest level for low-performing students. This loop crosses sectors of the model and is indicated by a minus sign in parentheses. This is a traditional symbol for thermostat loops (i.e., for negative feedback loops). A simpler negative feedback loop - around the level of tutoring and support for low-performing students-is illustrated in Figure 12. (Note 21)

To reiterate, this loop - which is hypothesized to increase the level of tutoring and support for students inversely (see the minus sign) proportional to their level of academic (and behavioral) performance - exemplifies strong leader behavior to stabilize student performance in the school, to work against achievement gaps as a matter of policy in the allocation of resources.

\section{A School-Focused Model}

In the next stage of the work-still a transitional stage on the road to a full-fledged computer simulation model-I have focused, mainly, on elements internal to the school. The following diagram-which as a whole is visually quite complex - includes only a few exogenous variables.

If I am correct in my theory of the dynamics of effectiveness of schooling, most of the feedback dynamics are positive, that is, self-reinforcing (which can be self-reinforcing in either direction, toward great or lesser effectiveness). However, there are important negative ("thermostat-type") loops that operate as control or constraint mechanisms in the model (see Figure 13) (Note 22). For example, there is a negative loop that, through "extra academic help" (e.g., tutoring programs), works to bring all students up to at least "minimum school expectations for student achievement." There is a similar thermostat-type loop that, through "teacher recruitment, evaluation, and professional development," operates to maintain "teacher quality" up to "expectations for teacher quality." In both cases, expectations are keyed to the "quality of school leadership," portraying the idea that strong school leaders set high standards for teacher quality. However, also in both cases, "costs" operate as a constraint (in other negative feedback loops) to restrain "extra academic help" and "teacher recruitment, evaluation, and professional development." One can see illustrated in this model the broad theory that the various instructional and interpersonal policies and practices that constitute the "tools" of effective schooling reinforce one another to raise, maintain, or lower student achievement, subject to the quality of community and school leadership and constrained by costs as a proportion of community resources.

\section{The Dynamics of School Leadership}

The quality of school leadership is keyed to the strength and direction of community leadership (see Figure 15). While, as indicated in Figure 14 (Note 23), the quality and educational orientation of community leadership is significantly subject to chance, it also seems true (although lacking hard evidence) that as student achievement improves the probability of attracting strong, school-oriented community leadership seems to improve, too. There is, however, an active control loop that is part of the dynamics of leadership (marked by a (-) sign in the loop: as aggregate student academic achievement lags below community expectations, there is pressure to improve the 
quality of school leadership (within the limits of school resources).

\section{The Dynamics of Extra Help}

The concept of "extra help" carries a heavy conceptual load in this model. It can mean anything from tutoring to help close the achievement gap for students achieving below-average on standardized tests to a wide variety of instructional policies and practices to assist all students in meeting very high expectations, in academics but also in all the areas of competence discussed by writers such as Richard Rothstein (2004) and Tony Wagner (2008). Notice that such an array of educational interventions, many on the cutting edge of research and practice, are driven importantly by the quality of school leadership and teaching (see Figure 15) (Note 24).

\section{The Dynamics of Teacher Quality}

The literature is replete with research and disputes about the importance of teacher quality for student achievement, and how to define, attain, and about its distribution among schools and school districts (Clotfelter, et al., 2007; Darling-Hammond, et al., 1983; Darling-Hammond, et al., 1998a; Darling-Hammond, et al., 1998b; Darling-Hammond, 1999; Darling-Hammond, 2000; Darling-Hammond, et al., 2001; Fenstermacher and Richardson, 2005; Iongewaard (2004); McCaffrey, et al., 2003; Peske and Haycock, 2006) (see Figure 16) (Note 25).

\section{Other Potential Negative Feedback Loops in the Current Model}

A careful examination of the "School-focused Student Achievement Model" (Figure 14) would reveal additional variables for which goals could be set and control loops established such, for example, as "Student Resilience" and "Student Aspirations." However, to do so would require determining the metrics by which the changing state of these variables could be known and also intervention programs that directly target these variables, programs that could be ramped up to close perceived gaps between the measured values of these variables and whatever "expectations" were established for them. Just thinking about these possibilities, though, highlights the importance to leadership of metrics, expectations, and known interventions (i.e., "treatments") in the form of policies and practices to maintain various system "states" consistent with high expectations.

\subsection{Further Thoughts about Negative Feedback Loops}

Other policies may involve creating new goal-oriented control loops that currently don't exist in the model. It seems especially important for leadership to envision policies that seek to bring initially exogenous variables into the "problem solution structure." For example, if — as has been well established-poor, African-American, and Latino children fall significantly behind White and Asian children in measures of mental functioning by the time they are two or three years old, then creating "thermostat" loops to counter intellectually aversive parenting and cultural practices can (and have) been seen as useful practices. In practice, counter-strategies like this can take the form of parent training and early childhood education such as those that have been made operational by Geoffrey Canada in the Harlem Children's Zone.

In an even larger context, policies might be put in place at state and national levels to deal with poverty and/or specific effects of poverty such as nutrition and health care for pregnant women and for young children, school children, and their mothers (Rothstein, 2004). In fact, of course, such programs (e.g., food stamps) have been put in place or advocated (e.g., universal health care).

So, in the next stages of this project it is my intent to clarify the causal-influence loop structures embedded in the model, to add new structures that are currently missing, to translate the model into a set of mathematical equations, and to use the model to assess the likely impact of different policy interventions on the problem system, on the likelihood of closing the achievement gaps, and on the implications of these theoretical understandings for how schools can become "opportunity givers" for initially low-achieving students.

\section{Next Steps}

In this paper I have laid out two theoretical models. The first was a broad model that depicted the influences of an extensive (although not complete (Note 26)) array of factors on the pre-school development and in-school achievement of students. This model included, in addition to in-school factors such as school leadership, teacher quality, emphasis on rigorous courses for all students, some important (although exogenous) factors such as family characteristics and parenting practices, and community characteristics such as wealth, crime, and level of support for schools.

A second, school-focused model is also included in the paper. This model emphasizes, in a more centered way, some interconnected "causal-influence" diagrams that include a set of variables that are directly related to student achievement and that are under the substantial influence of school leaders and staff. Even the quality of 
community leadership and the extent of its orientation to schooling can be significantly influenced, in an important number of cases, by high quality school leaders. As I have suggested in the previous text, I believe that this model emphasizes the importance of school and community leadership, their collective impact on instructional standards, teacher quality, multiple aspects of rigorous instruction and targeted help for all students, parent involvement and relationship building, and on the counter-effects of (a) student achievement on school leadership and (b) school leadership on community leadership and support for schools.

For example, in retrospect Michelle Rhee talked about this aspect of high quality school leadership:

Looking back, Michelle Rhee says there are a few things she didn't do successfully during her three years as chancellor of the District of Columbia public schools. One: She failed to engage and mobilize parents, residents and community leaders who supported her ambitious education reform agenda, but were never vocal about it. (Associated Press, January 10, 2011)

Furthermore, in discussing the establishment and agenda of her new advocacy group, "StudentsFirst," she highlighted further the opportunity and responsibility of leaders to build community support for school reform:

A lot of the reason I started the group is so we can provide the cover a courageous political leader needs to push this agenda," she said. "In these incredibly tough budget times, when school districts will take a big hit, we have an opportunity to rethink public education and put students first. (Wall Street Journal Online, 2011)

The next stage in this work-in-progress is to move from "causal influence" diagramming, which highlights the influence of multiple factors on each other in a general sense to "stock-and-flow" models (Richmond, 1992) that get beyond a laundry list of largely external factors, that develop a theory of how rates of increase and decrease (i.e., inflow and outflow) affect over time the levels of such model variables as teacher quality, help for underachieving students, student motivation, self-efficacy, and resilience, and the quality of school and community leadership.

Such models can be run as computer simulations, tested, and analyzed to understand the dynamics that are producing the problematic trend - in this case the systematic divergence in school achievement commonly called "achievement gaps." Once validated — not as "true" but as realistic and useful — these models can be used not only to understand the problem system but to imagine and test changes (i.e., policies) to improve the performance of the problem system (in this case, of the school). As Richmond (1992) put it:

In Systems Thinking, "impacts/drives/influences" is not good enough. Systems Thinkers are striving to capture causality [emphasis in the original] -i.e., how things actually work. (p. 46)

So, the next stage of the work is a model-building and testing stage.

\section{References}

Associated Press. (2011). Ex DC School Chief Takes Reform Message Nationwide. January 10.

Borman, Geoffrey D., et al. (Summer 2003). Comprehensive School Reform and Achievement: A Meta-Analysis. Review of Educational Research, 73(2). http://dx.doi.org/10.3102/00346543073002125

Bowen, William G., \& Bok, Derek. (1998). The Shape of the River: Long-Term Consequences of Considering Race in College and University Admissions. Princeton, NJ: Princeton University Press.

Carneiro, Pedro, \& Heckman, James. (2002). "Human Capital Policy." Paper presented at the Alvin Hansen Seminar, Harvard University, April 25, revised August.

Clauset, Karl H., Jr. (1982). Effective Schooling: A Systems Dynamics Policy Study. Unpublished dissertation, Boston University.

Clauset, Karl H., Jr., \& Alan K. Gaynor. (December, 1982). Effective Schooling: A System Perspective. Educational Leadership.

Clauset, Karl H., Jr., \& Gaynor, Alan K. (1992). Educational Policy Analysis: An Analysis of Effective and Ineffective Schools Using the System Dynamics Method. Analysis of Dynamic Psychological Systems, Vol. 2, New York: Plenum Publishing Corporation ,303-325

Clotfelter, Charles, et al. (March, 2007). High-Poverty Schools and the Distribution of Teachers and Principals, [Online]

Available:

http://74.125.95.132/search?q=cache:IxHkJbyjNnIJ:www.caldercenter.org/PDF/1001057_High_Poverty.pdf+clotfelt er+high+poverty+schools\&cd=6\&hl=en\&ct=clnk\&gl=us\&client=firefox-a

Darling-Hammond, Linda, Wise, Arthur E., \& Pease, Sara R. (Fall, 1983). Teacher Evaluation in the Organizational 
Context: A Review of the Literature. Review of Educational Research, 53(3), 285-328. http://dx.doi.org/10.2307/1170367

Darling-Hammond, Linda, Cobb, Velma, \& Bullmaster, Marcella (1998a). "Professional Development Schools as Contexts for Teacher Learning and Leadership", In Leithwood and Louis (eds), Organizational Learning in Schools.

Darling-Hammond, Linda. (December, 1999). Teacher Quality and Student Achievement: A Review of State Policy Evidence. Center for the Study of Teaching and Policy, University of Washington.

Darling-Hammond, Linda, Cobb, Velma, and Bullmaster, Marcella (1998b). "Professional Development Schools as Contexts for Teacher Learning and Leadership" In Leithwood and Louis (eds), Organizational Learning in Schools. Routledge.

Darling-Hammond, Linda, Berry, Barnett, \& Thoreson, Amy. (Spring, 2001). Does Teacher Certification Matter? Evaluating the Evidence. Educational Evaluation and Policy Analysis, 23(1), 57-77. http://dx.doi.org/10.3102/01623737023001057

Darling-Hammond, Linda. (February 2000). Reforming Teacher Preparation and Licensing: Debating the Evidence. Teachers College Record, 102(1), 28-56. http://dx.doi.org/10.1111/0161-4681.00047

Dehaene, Stanislas. (2009). Reading in the Brain: The Science and Evolution of Human Invention. Viking Penguin.

Fenstermacher, Gary D., and Richardson, Virginia. (January 2005). On Making Determinations of Quality in Teaching. Teachers College Record, 107(1), 186-213. http://dx.doi.org/10.1111/j.1467-9620.2005.00462.x

Gladwell, Malcolm. (2008). Outliers. Little, Brown Publishing.

Jencks, Christoper. (1979). Who Gets Ahead? New York: Basic Books.

Jencks, Christopher, \& Phillips, Meredith. (1998). The Black-White Test Score Gap. Washington, D. C.: The Brookings Institution Press.

Jongewaard, Steven M. (2004). Teachers at Risk: Preparing Effective Teachers for 21st Century Schools. A paper prepared for the Oxford Round Table on At-Risk Students, Oriel College, Oxford University, March 21-26, 2004. [Online]

Available:

http://74.125.47.132/search?q=cache:TLALpqTNjRMJ:www.agi.harvard.edu/Search/download.php\%3Fid\%3D118+ Teachers + at + Risk: + Preparing + Effective + Teachers + for $+21 \mathrm{st}+$ Century + Schools $\& c d=4 \& h l=e n \& c t=c l n k \& g l=u s$

Jussim, Lee. (October, 1986). Self-fulfilling Prophecies: A Theoretical and Integrative Review. Psychological Review, 93(4). http://dx.doi.org/10.1037/0033-295X.93.4.429

Kober, N. (2001, April). It takes more than testing: Closing the achievement. A report of the Center on Education Policy. Washington, DC: Center on Education Policy.

Masterov, Dimitriy V. (Center for Social Program Evaluation, University of Chicago). (2004). January 30. Personal Communication.

McCaffrey, Daniel F., et al. (2003). Evaluating Value-Added Models for Teacher Accountability. Prepared for the Carnegie Corporation. RAND Education.

McKenzie, \& Company (April 2009). Detailed findings on the economic impact of the achievement gap in America's schools.

Miller, L. S. (1995). An American Imperative: Accelerating Minority Educational Advancement. New Haven, CT: Yale University Press.

Murphy, Joseph (2010). The Educator's Handbook for Understanding and Closing Achievement Gaps. Thousand Oaks, CA: Corwin.

Neuman, S. B. (2003). From Rhetoric to Reality: The Case for High-Quality Compensatory Prekindergarten Programs. Kappan, 85, 286-291

Neuman, S. B. (2006). The Knowledge Gap: Implications for Early Education. In Dickinson, David K., and Neuman, Susan B., Handbook of Early Literacy Research (Vol. 2). New York and London: The Guilford Press.

Parker, Ian. (May 17, 2010). The Poverty Lab: Transforming Development Economics: One Experiment at a Time. The New Yorker.

Pascale, Richard T., Sternin, Jerry, \& Sternin, Monique. (2010). The Power of Positive Deviance: How Unlikely Innovators Solve the World's Toughest Problems. Center for Public Leadership, John F. Kennedy School of Government, Harvard University. Harvard University Press. 
Paul, Annie Murphy. (2010). Origins: How the Nine Months Before Birth Shape the Rest of Our Lives. Simon and Schuster.

Peske, Heather G., \& Haycock, Kati. (June 15, 2006). Teaching Inequality: How Poor and Minority Students are Shortchanged on Teacher Quality. A report of the Education Trust. [Online] Available: http://www.forumforeducation.org/node/59

Richmond, Barry. (1992). An Introduction to Systems Thinking. Isee Systems.

Rist, Ray C. (1973). The Urban School: A Factory for Failure. Cambridge, MA: MIT Press.

Taleb, Nassim. (2010). The Black Swan: The Impact of the Highly Improbable. Random House.

Rothstein, Richard. (2004). Class And Schools: Using Social, Economic, And Educational Reform To Close The Black-white Achievement Gap. Economic Policy Institute.

Taleb, Nassim. (2008). Fooled by Randomness: The Hidden Role of Chance in Life and in the Markets. (2nd edition). Random House.

Tough, Paul. (2008). Whatever It Takes: Geoffrey Canada's Quest To change Harlem and America. Houghton-Mifflin.

Wagner, Tony. (2008, 2010). The Global Achievement Gap: Why Even Our Best Schools Don't Teach the New Survival Skills Our Children Need — and What We Can Do About It. Basic Books

Wall Street Journal Online. (2011). School Changes Pushed by Rhee. January 10, 2011

\section{Appendix}

Appendix 1. Model Figures

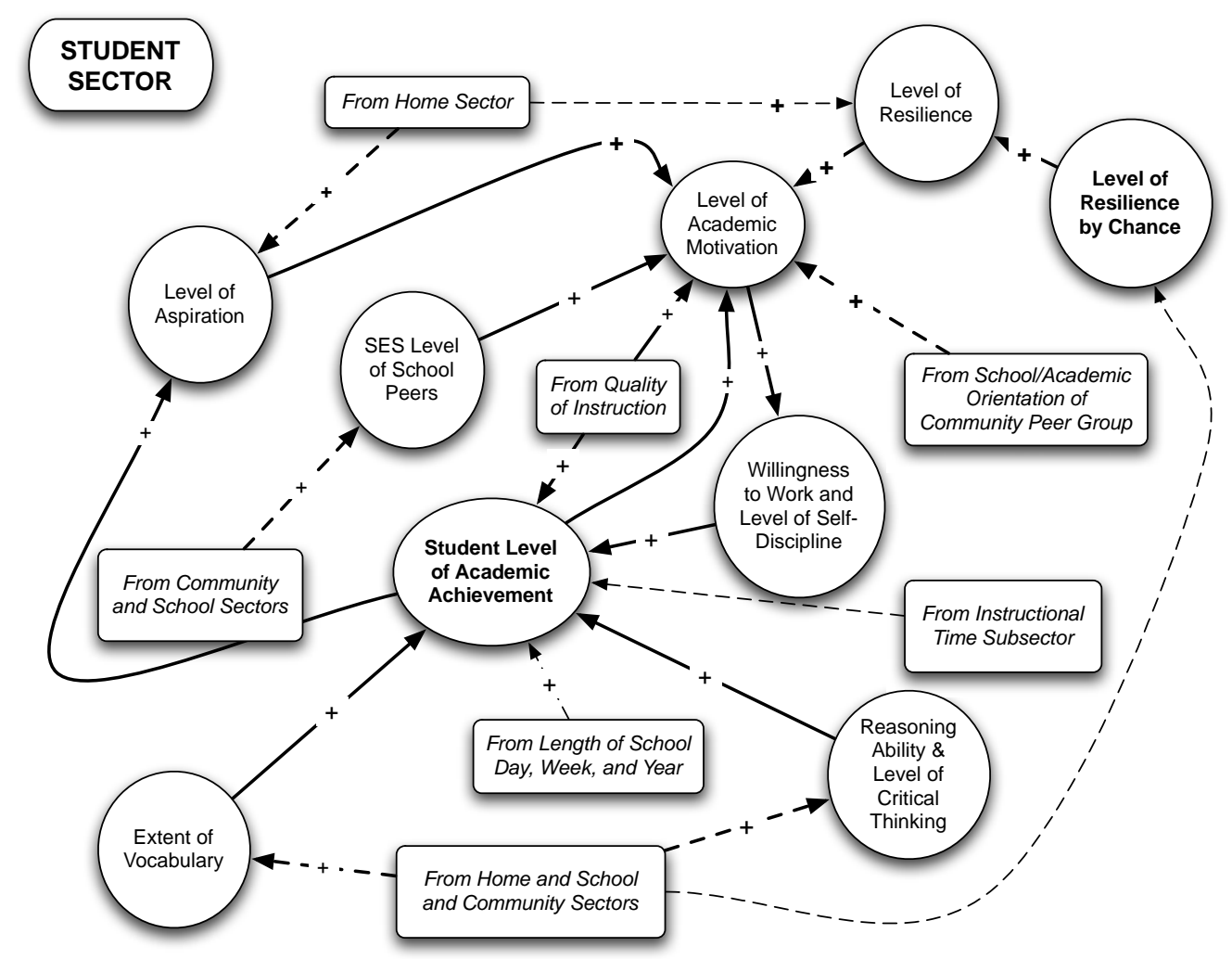

Figure 1. Achievement Gap Model: Student Sector 


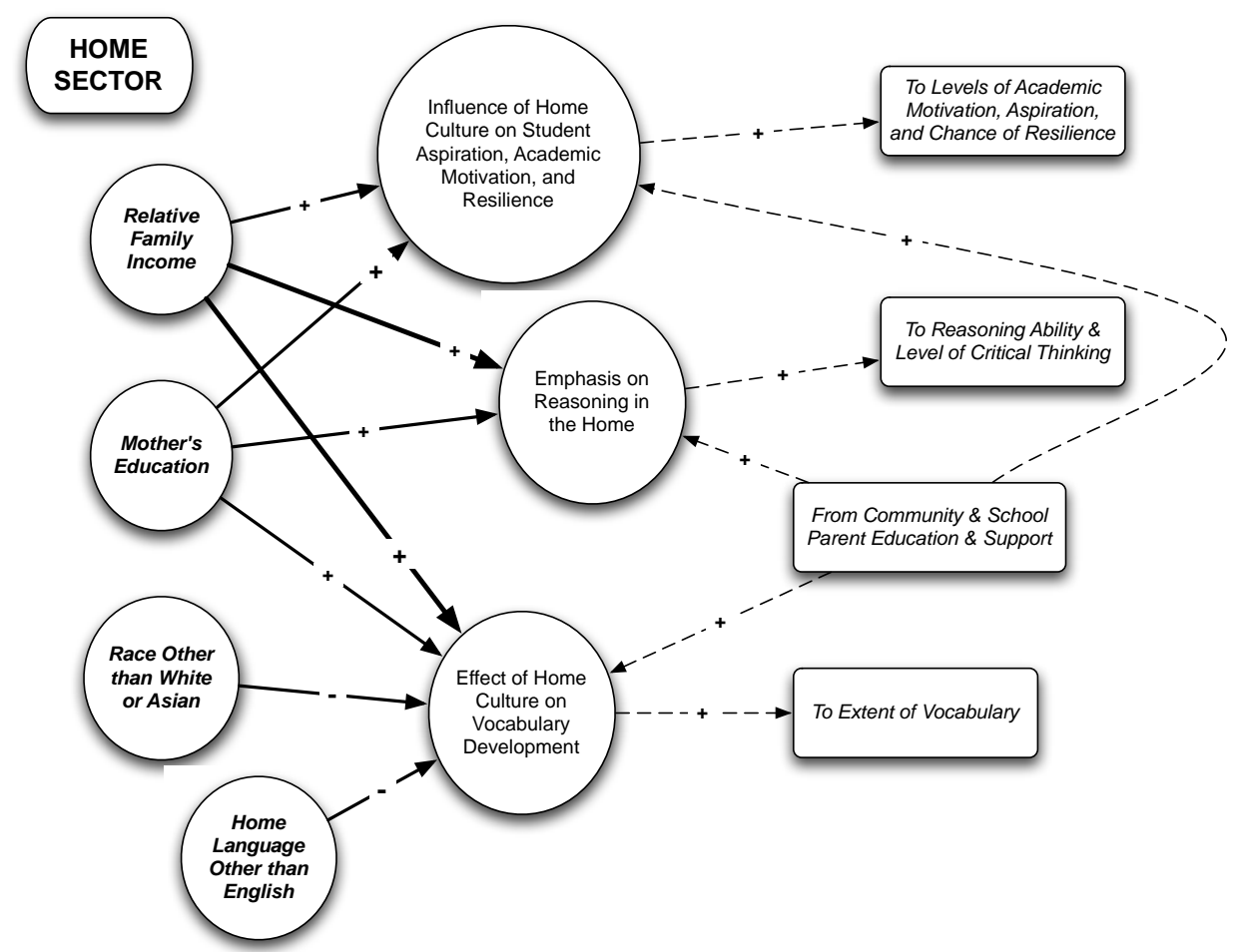

Figure 2. Achievement Gap Model: Home Sector 


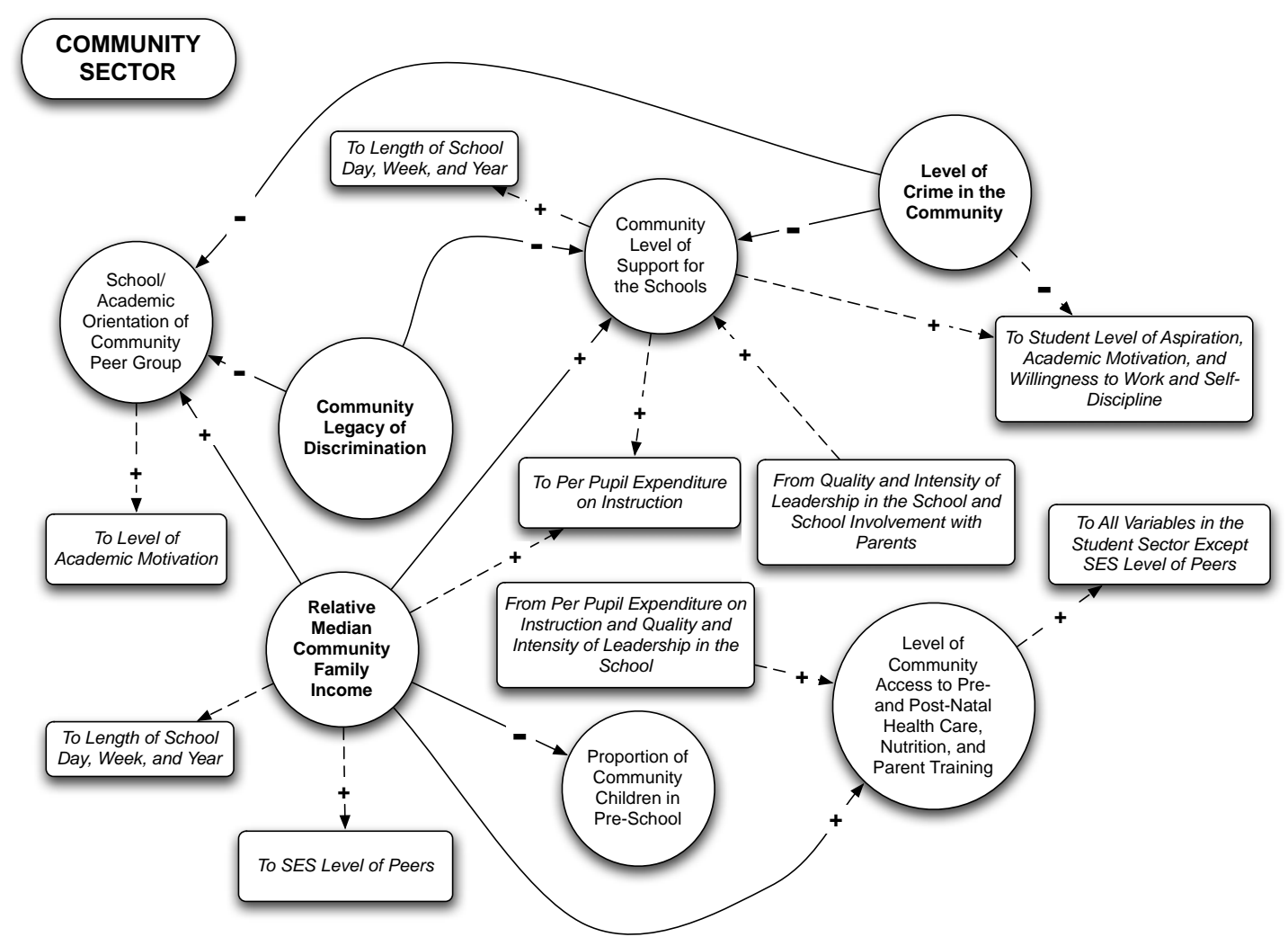

Figure 3. Achievement Gap Model: Community Sector

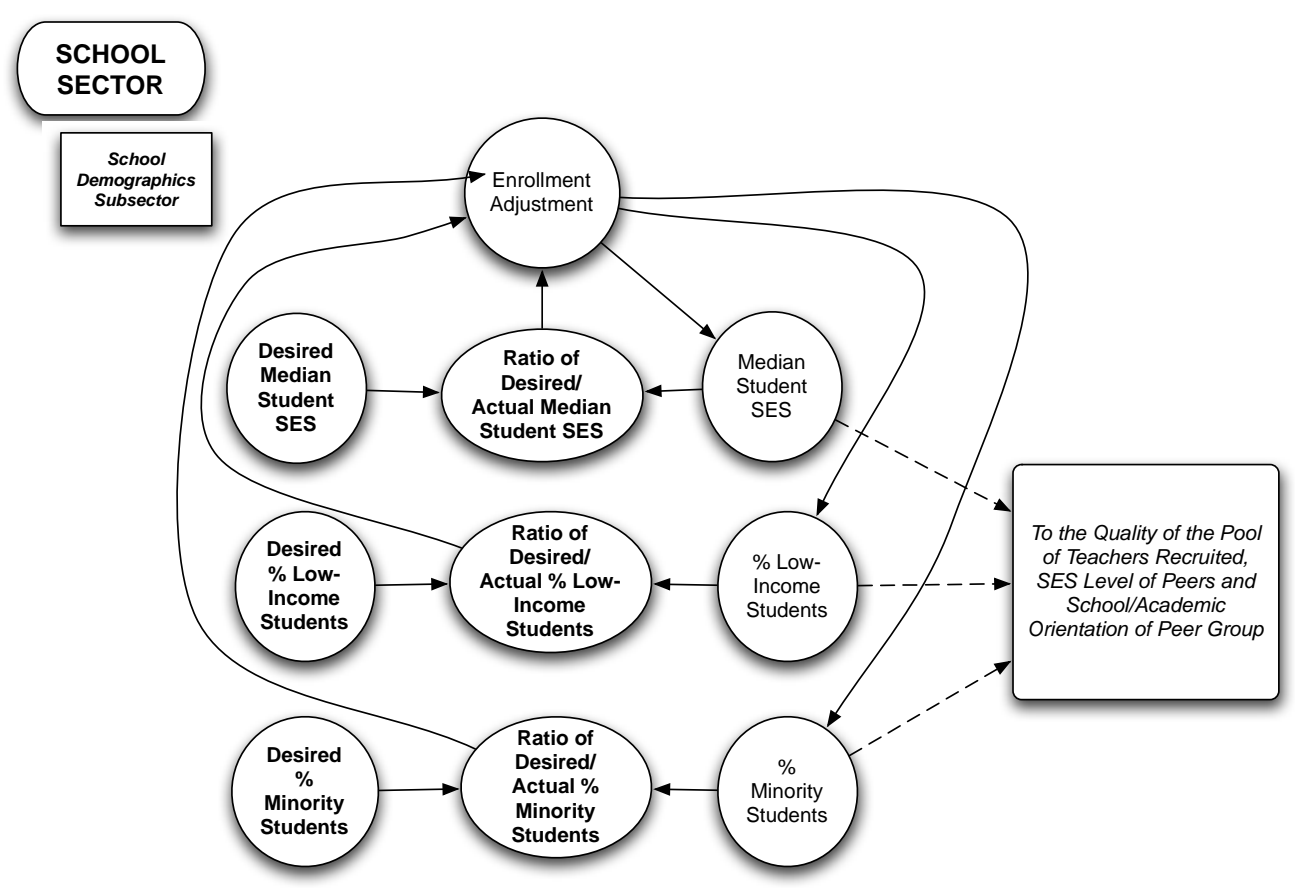

Figure 4. Achievement Gap Model: School Demographics Subsector 


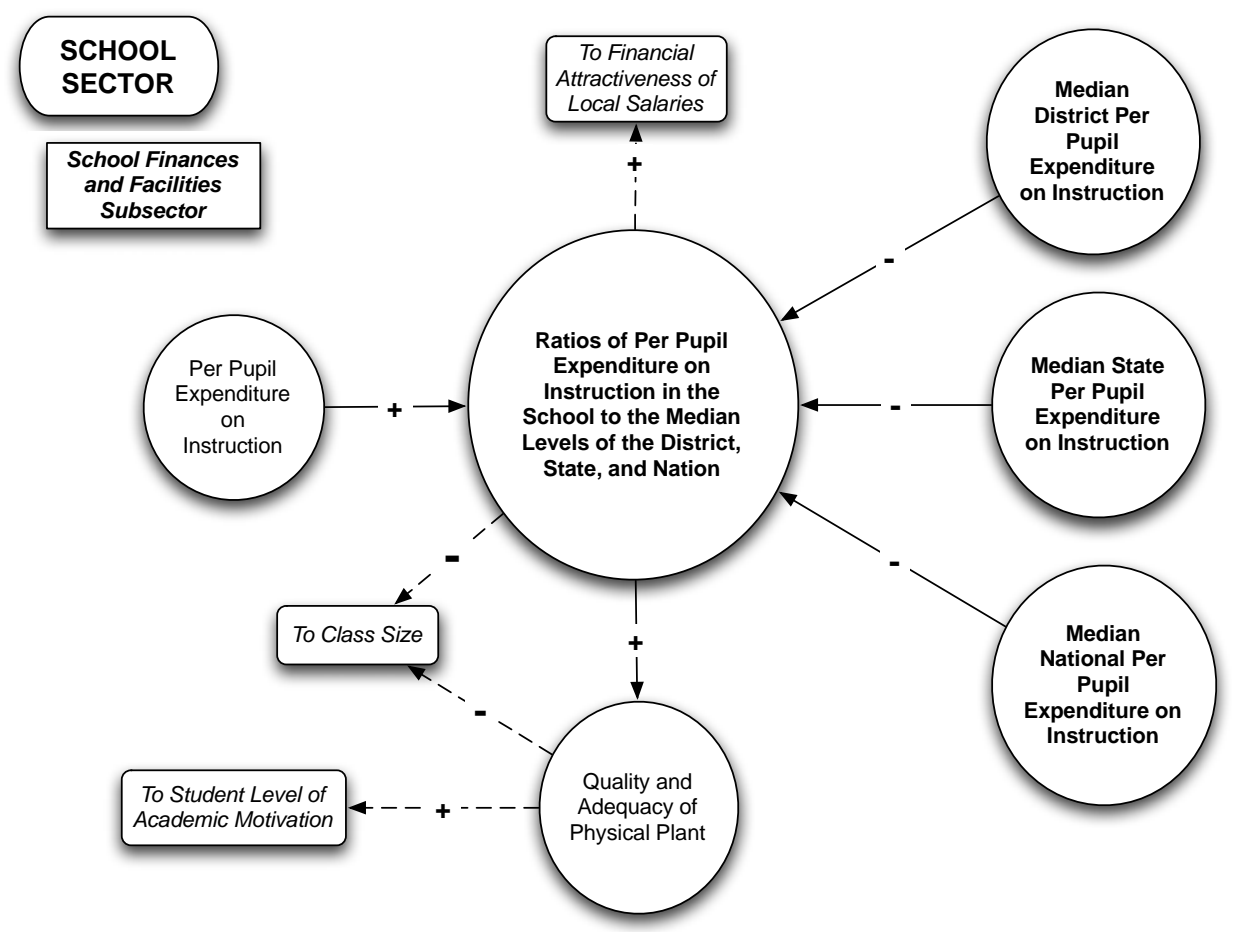

Figure 5. Achievement Gap Model: School Finances and Facilities Subsector

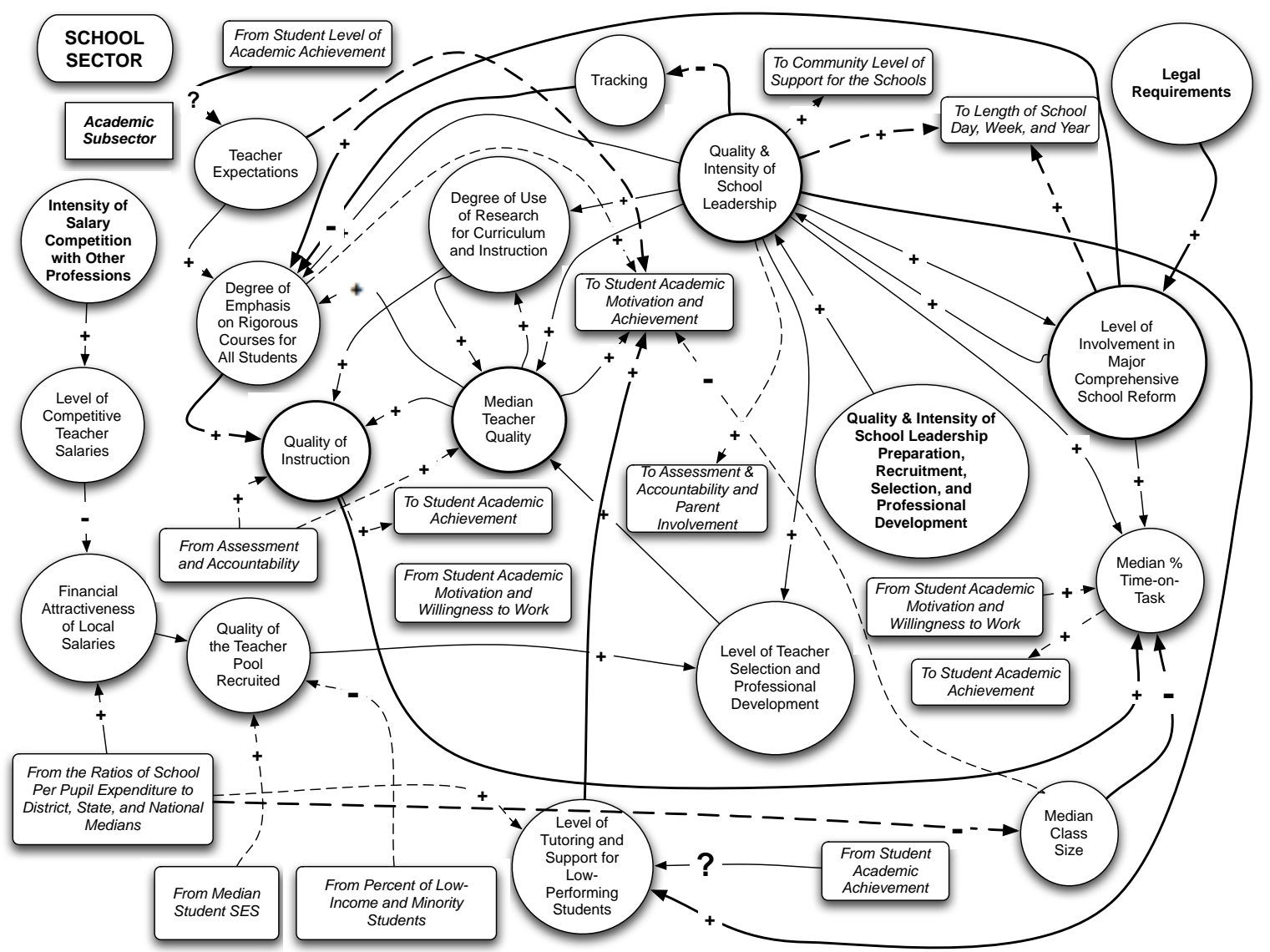

Figure 6. Achievement Gap Model: School Academic Subsector 


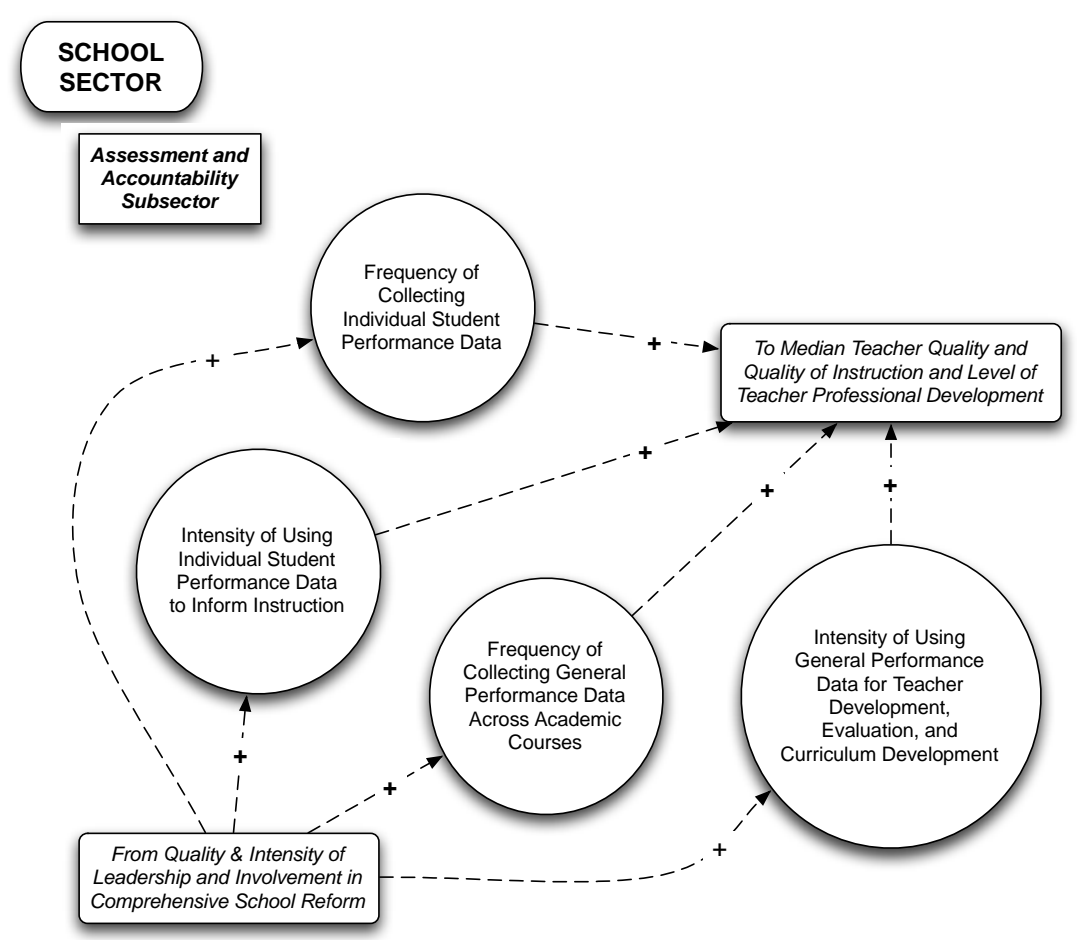

Figure 7. Achievement Gap Model: School Assessment and Accountability Subsector (Note 27)

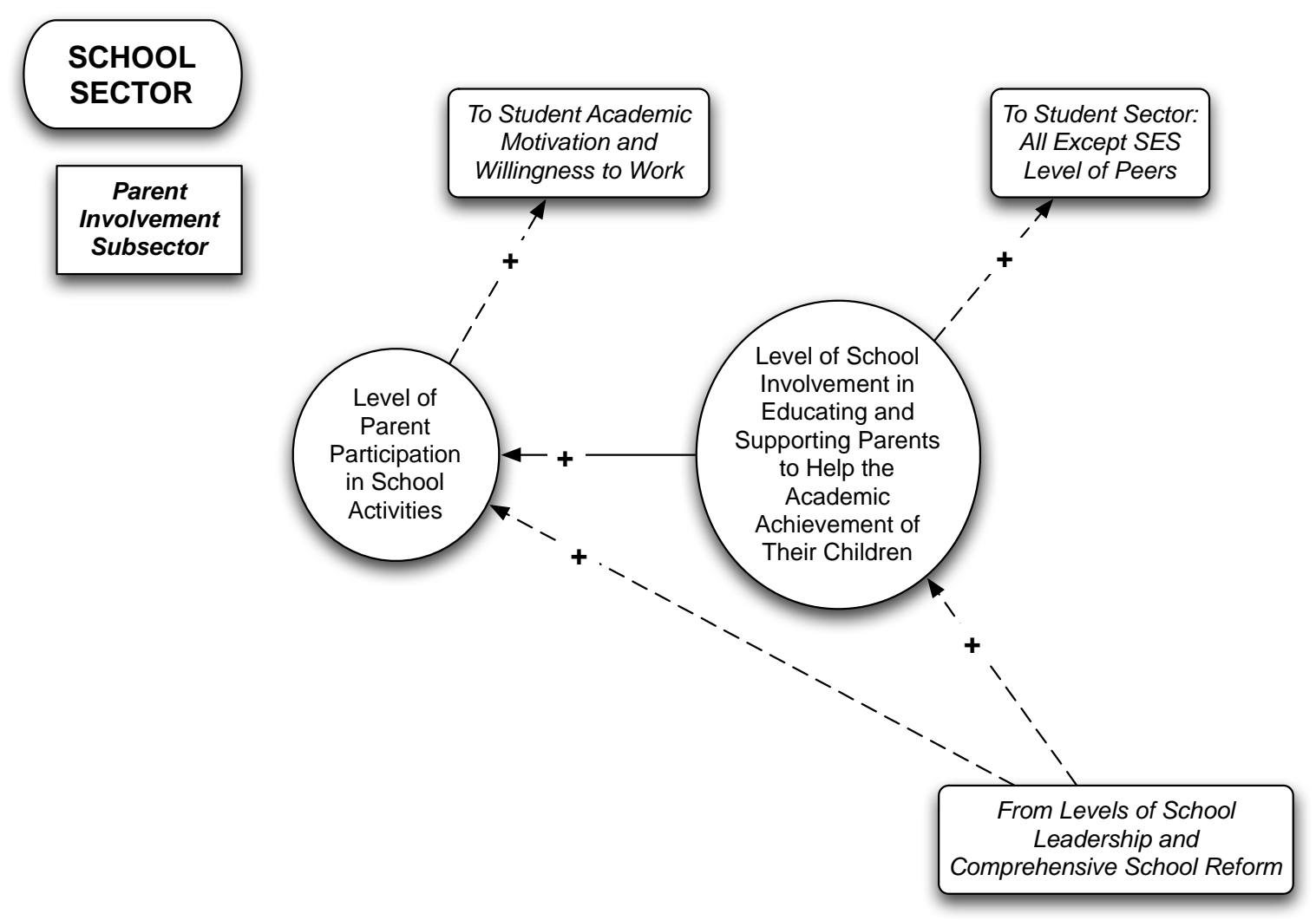

Figure 8. Achievement Gap Model: School Parent Involvement Subsector 


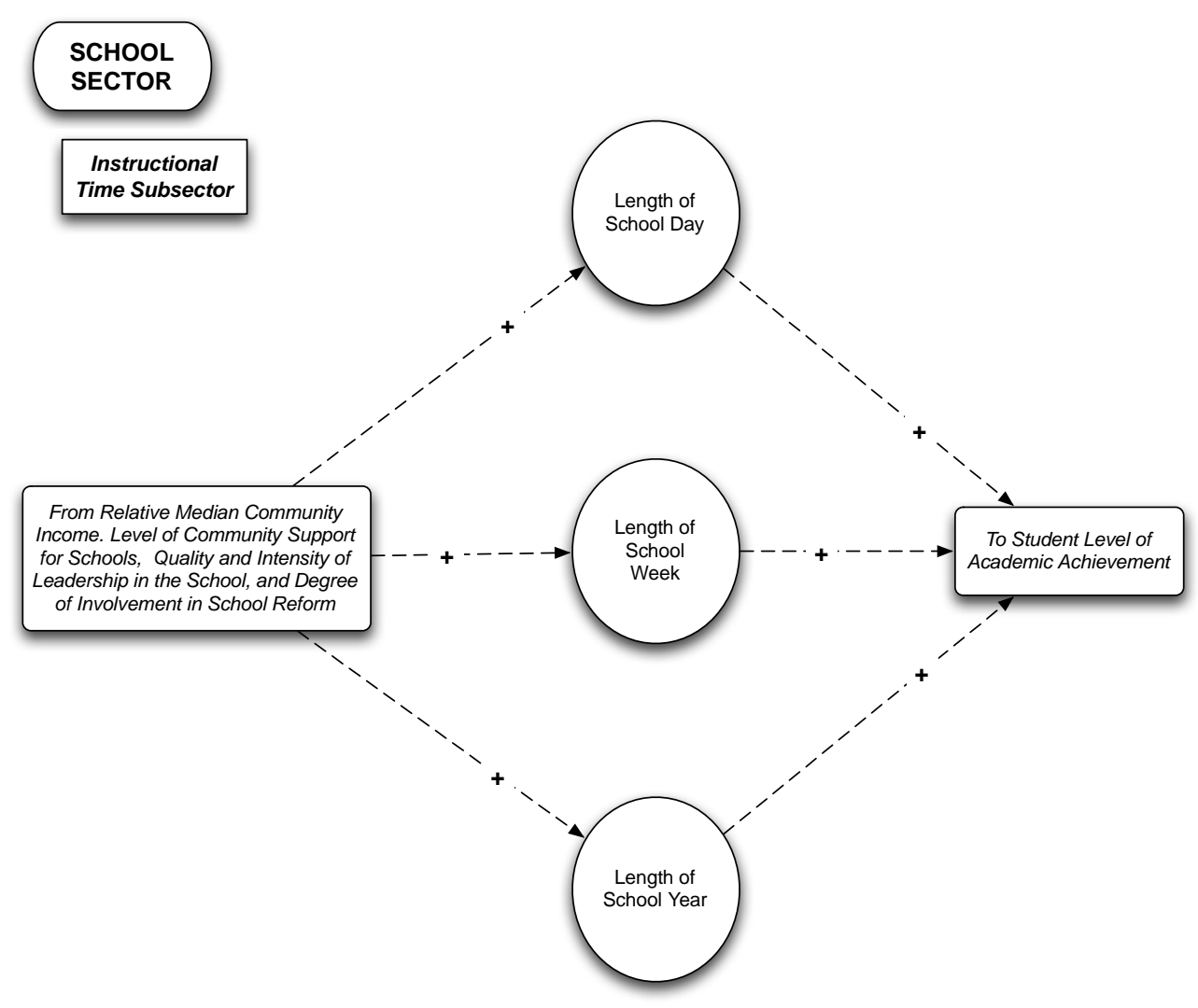

Figure 9. Achievement Gap Model: School Instructional Time Subsector

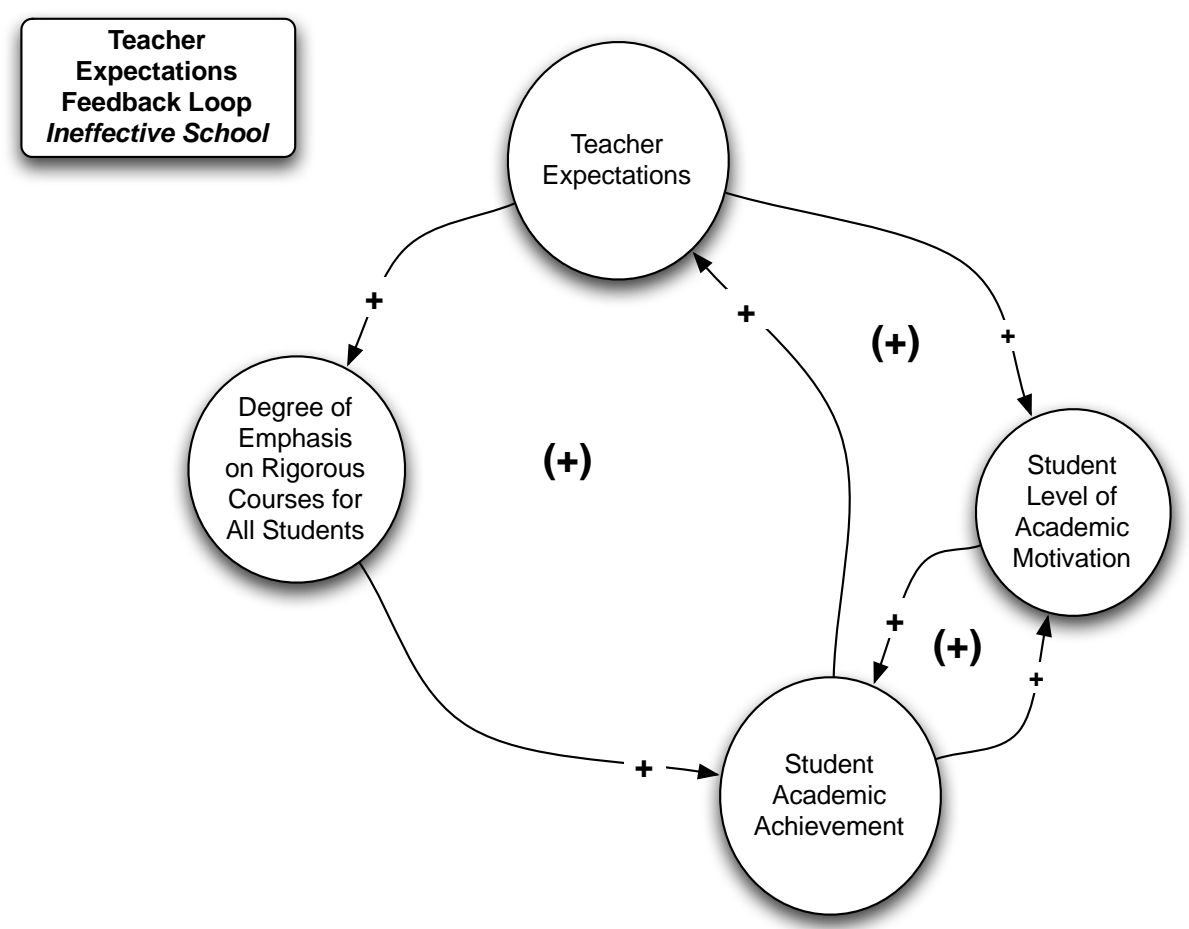

Figure 10. Achievement Gap Model: The Teacher Expectations Feedback Loop in an Ineffective School 


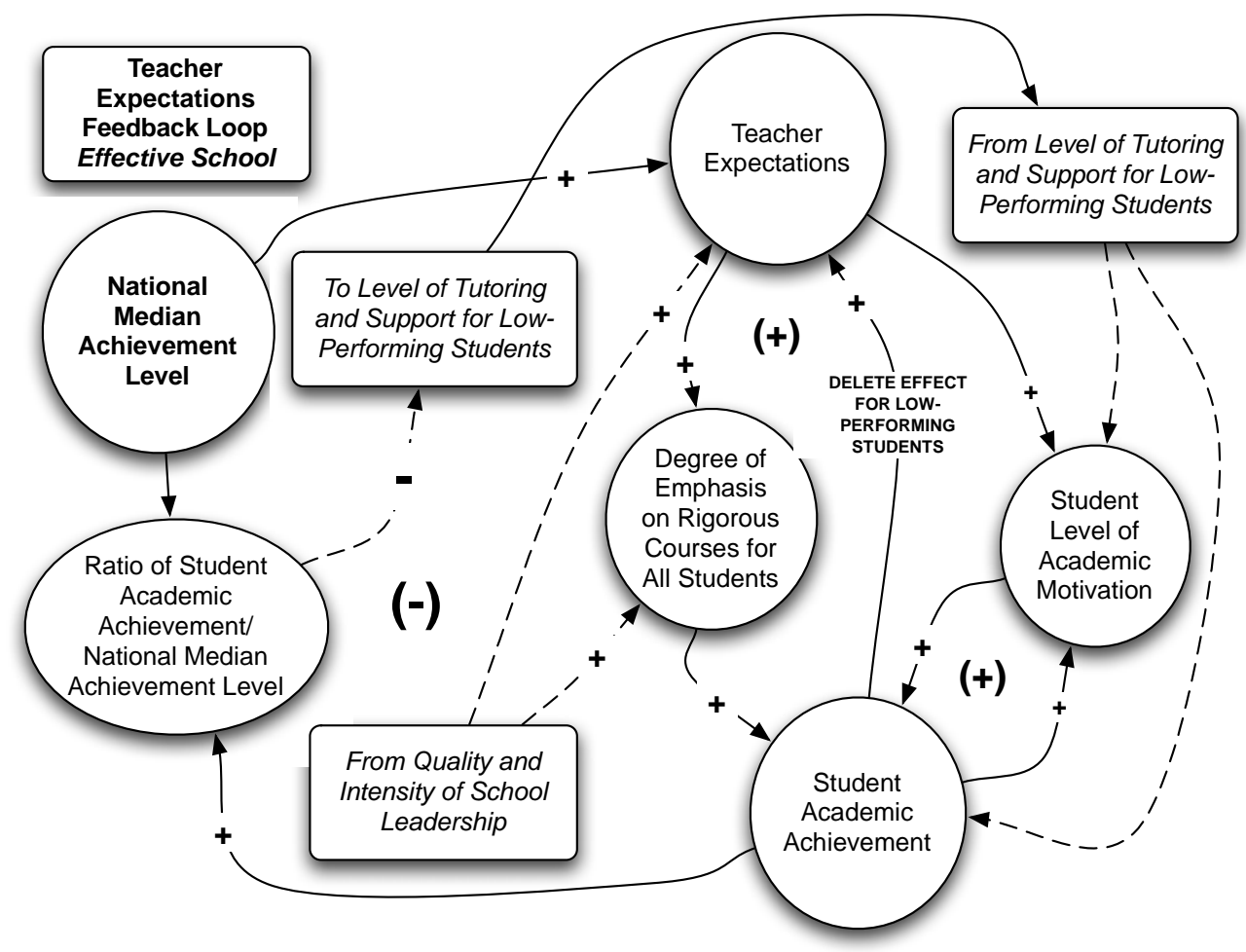

Figure 11. Achievement Gap Model: The Teacher Expectations Feedback Loop in an Effective School

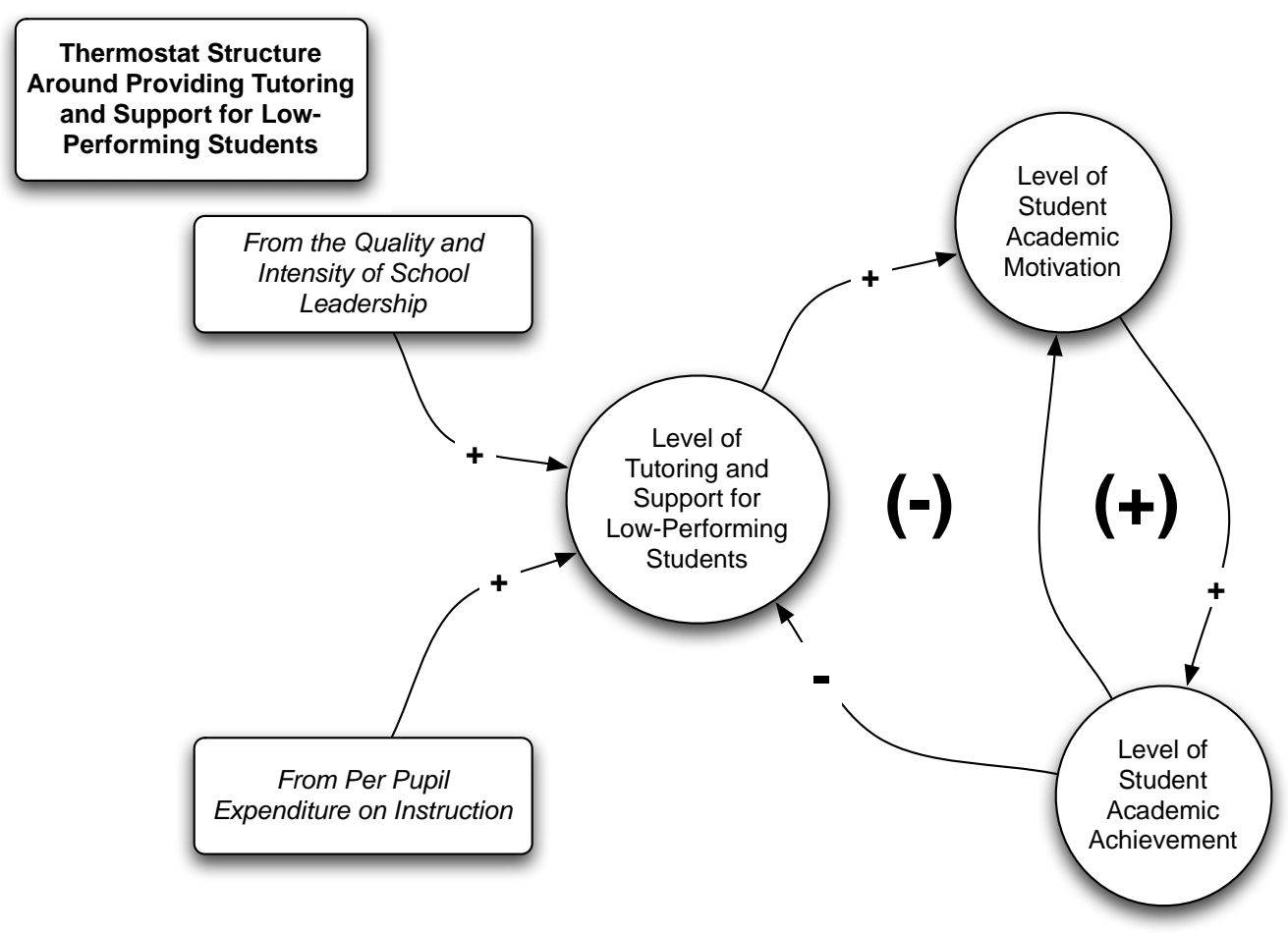

Figure 12. Achievement Gap Model: A Negative Feedback Loop Around Tutoring and Support for Low-Performing Students 


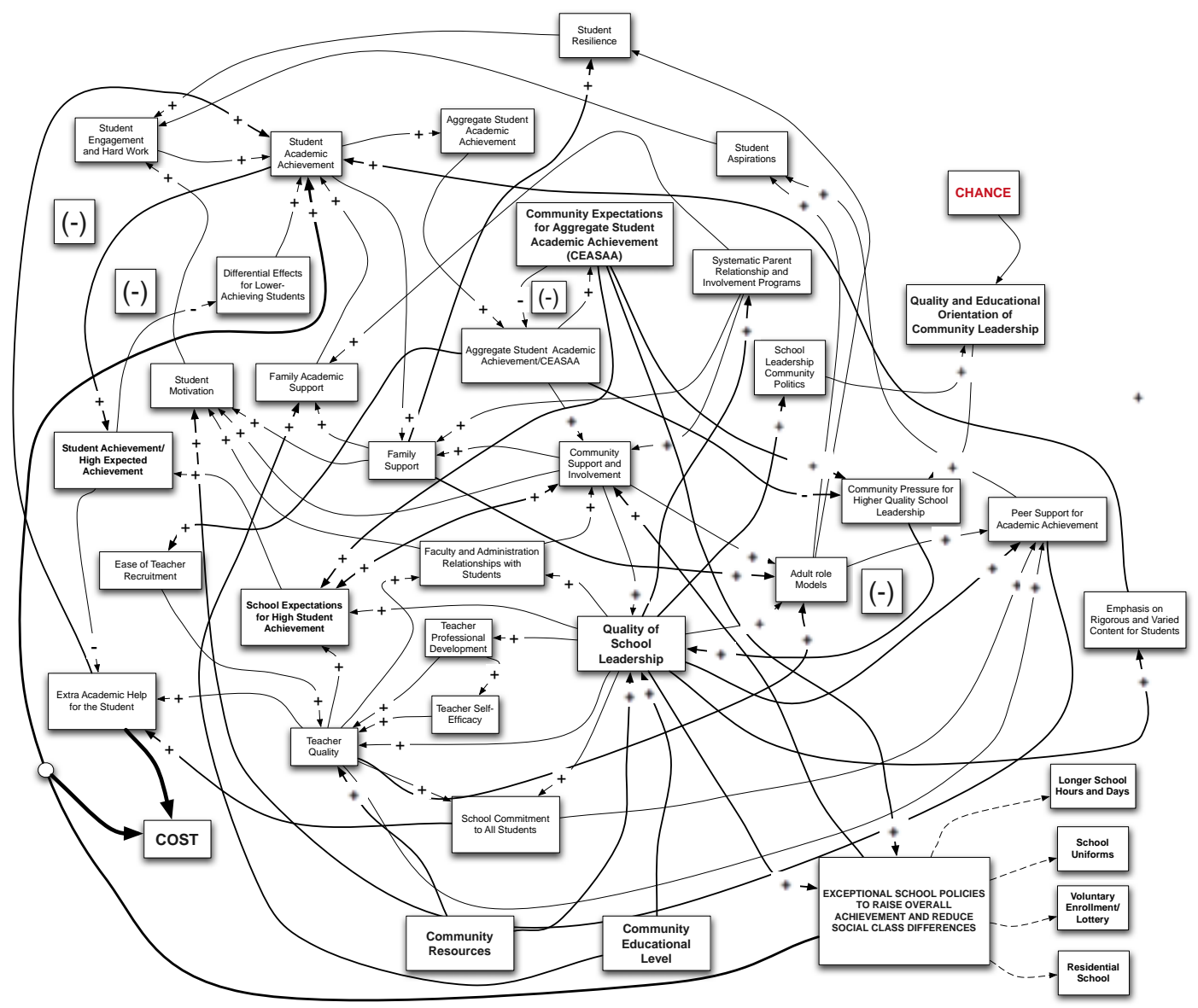

Figure 13. The School-Focused School Achievement Model

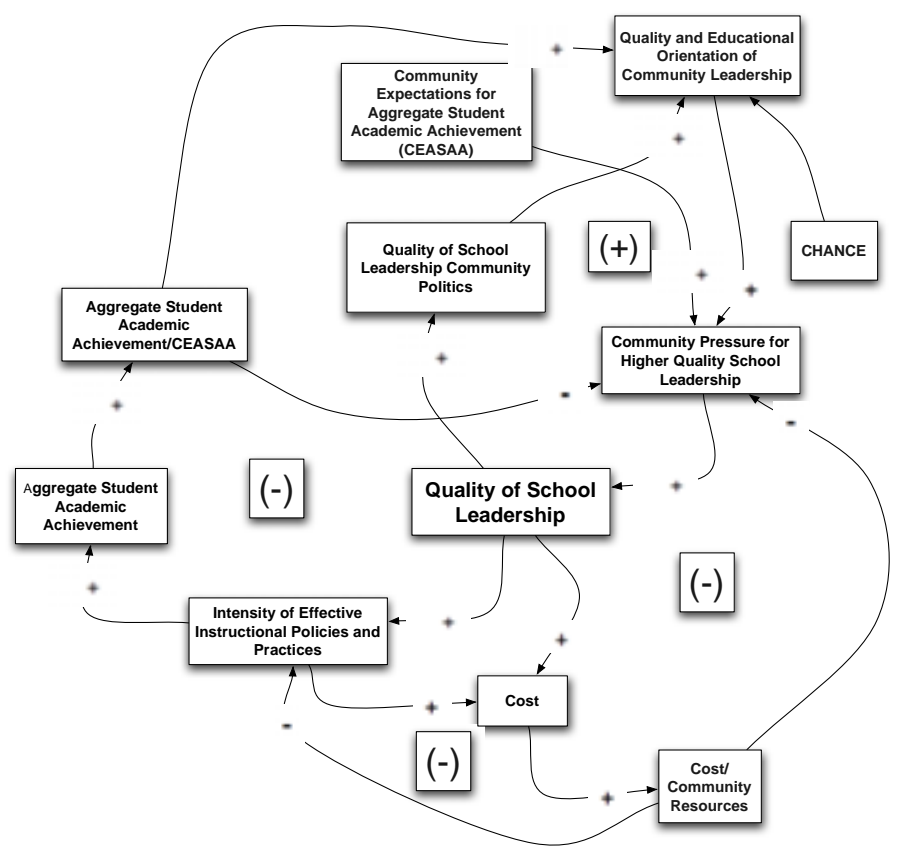

Figure 14. The Dynamics of Community and School Leadership 


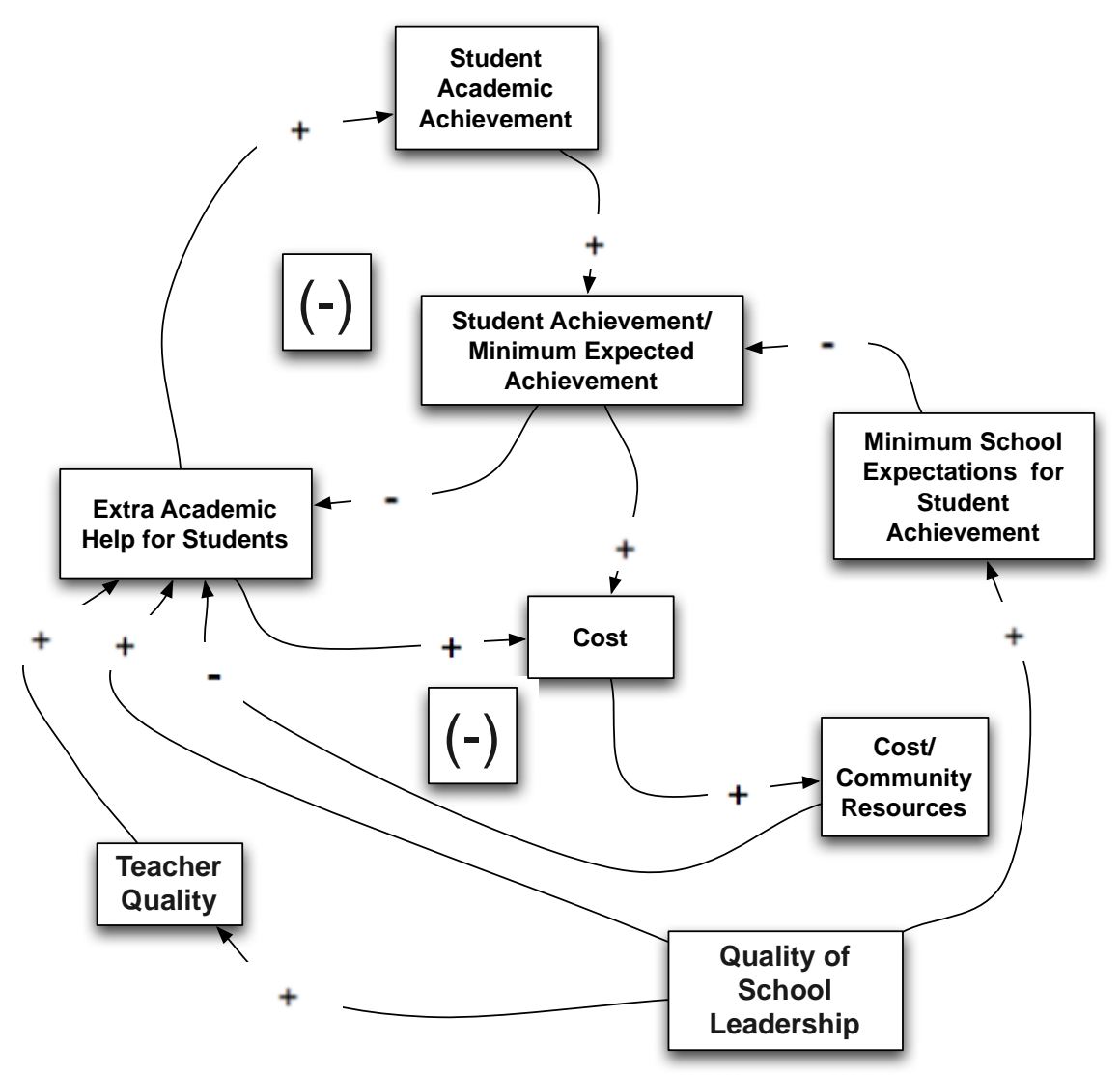

Figure 15. The Dynamics of Extra Help

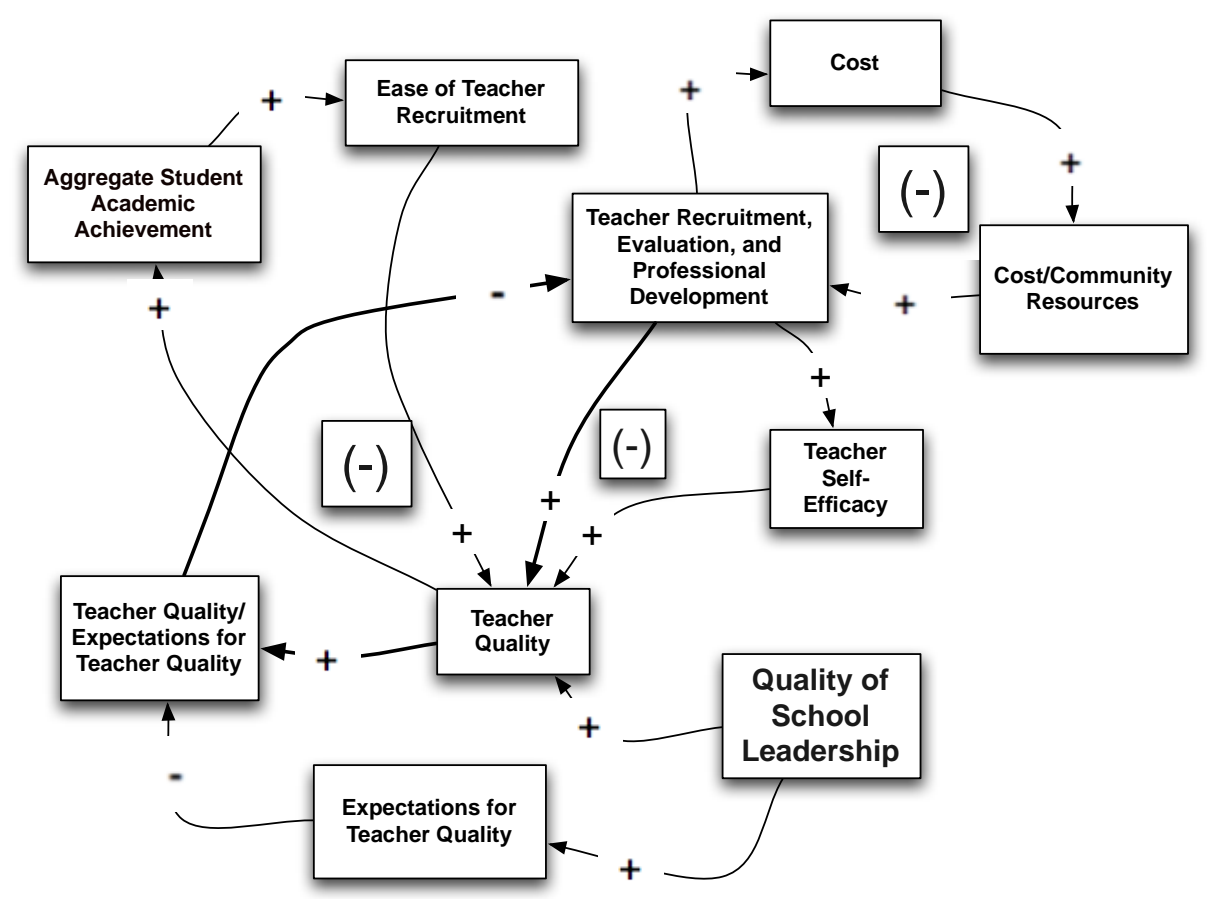

Figure 16. The Dynamics of Teacher Quality 


\section{Notes}

1. While I focus in this paper on the academic achievement gaps, it is also important to recognize that the issues of achievement transcend the cognitive dimension of student achievement, per se. Richard Rothstein, for example, in a critically important volume (Rothstein, 2004), takes the position that the field's policy interest in student achievement should go well beyond standardized test scores: "Obsessed with test scores, educators have devoted almost no effort to identifying or measuring non-cognitive skills" (p. 95). Referring, for example, to the work of "a team led by Christopher Jencks" (p. 98), Rothstein identifies other important "predictors of adult economic success" (p. 98) and, referring to the work of Bowen and Bok (in Rothstein, p. 104), predictors of students' adult level of activity "in community, social service, youth, educational, cultural, alumni, religious, and political groups" (p. 104): leadership ability; years of school completed; self-confidence; "anti-social" scores (Carneiro and Heckman, 2002 and Masterov, 2004, in Rothstein, pp. 99-100); self-discipline; ambition; a strong work ethic and moral code. Wagner (2008) takes a similar position in addressing the achievement gap between the United States and other countries.

2. I also include, prior to laying out the diagrams, a straightforward list of the variables and causal influences among them that are subsequently illustrated diagrammatically.

3. One more introductory observation: You will see, as you examine the diagrams, that I attach frequently words like "level of" to describe the variables. The reason for this is related to the ultimate nature of "dynamic systems modeling" and, therefore, to my longer-term goals for this policy analysis project. I plan to write equations-in the tradition of the field of System Dynamics - specifying in quantitative terms the causal relationships suggested in these "causal influence" diagrams. Thus, ultimately, the model will be described mathematically, translating understandings that are, in the first instance, qualitative into a mathematical model. While I believe that models of this type express understandings that, at root, are deeply qualitative in nature, it is necessary to describe the model variables in terms that suggest quantification. "Level" is one of these terms.

4. For example, in the 2008 financial crisis, the stimulus package in the United States did not, and could not be expected to, produce the desired effects immediately, but only, in some respects, over a fairly long time frame. As a case in point, job growth has historically been delayed as an economy pulls out of a serious downturn.

5. In a very recent book, Richard Pascale, Jerry Sternin, and Monique Sternin describe and advocate a pragmatic approach to the design of intervention strategies that they have used worldwide in addressing a range of problems associated with global poverty. They provide examples in practice in a book entitled The Power of Positive Deviance: How Unlikely Innovators Solve the World's Toughest Problems (2010). These respected development experts advocate what is essentially an atheoretical, "on-the-ground" idea for solving seemingly intractable problems - perhaps like the achievement gap problem. And in doing so, they advocate a procedure fundamentally different from the analytic strategy I take in this essay. However, their approach seems to me to have a central flaw with respect to closing the academic achievement gaps in American education. The key difficulty in their scheme is that it is a local strategy, drawing in each case separately and inductively from the experiences and practices of locally indigenous people. Adopting this as a gap-closing strategy across American schools would seem to require a series of fragmented efforts limited in each case to a particular school or school-district community, repeated endlessly across all the schools and school districts in the nation. So, while their positive-deviancy scheme undoubtedly has advantages in particular situations, and perhaps a more general worth in suggesting key variables and parameters for an analytic model, its value seems limited by its fundamental lack of generalizability.

\section{See Appendix, "Model Figures,” Figure 1, "Achievement Gap Model: Student Sector.”}

7. The "Student Level of Academic Achievement" is generally considered the primary dependent variable of this "problem system," since the problem is characterized as one of a persistent gap in academic achievement. It should be recognized, however, that many variables in this problem system are important and also that the student level of academic achievement is not simply a "dependent" variable. In fact, as can be seen in the diagrams, it is involved in multiple inter-causal relationships in which multiple variables, either directly or indirectly, are involved in circular or reciprocal causal relationships, often crossing multiple sectors of the problem system.

8. See Appendix, "Model Figures,” Figure 2, “Achievement Gap Model: Home Sector."

9. See Appendix, "Model Figures," Figure 3, “Achievement Gap Model: Community Sector."

10. See Appendix, "Model Figures," Figure 4, "Achievement Gap Model: School Demographics Sub-Sector."

11. See Appendix, "Model Figures," Figure 5, "Achievement Gap Model: School Finance and Facilities Sub-Sector." 
12. See Appendix, "Model Figures,” Figure 6, "Achievement Gap Model: School Academics Sub-Sector."

13. The concept of intensity covers a number of elements of teaching, including the depth of content, using class time efficiently, and an emphasis on student engagement. This can be well understood in the context of the following anecdote related by Susan Neuman:

Recently I visited several prekindergarten classes specifically targeted for poor children. Throughout the 3-hour visit, I counted 20 minutes of instruction in these classrooms. Rather than instruction, the day was overtaken by transitions (late arrivals, early dismissals, lunch, bathroom washing, getting ready for outdoor play, getting back from outdoor play, going to and from "specials," cleaning up). Even more troubling, however, was the type of instruction I observed in early literacy and mathematics within those precious 20 minutes. . . And throughout these individual exercises (described in elided text), not once was there an effort to engage children's minds through stimulating content learning (Neuman, 2003, in Neuman, 2006, pp. 34-35).

14. See Appendix, "Model Figures," Figure 7, "Achievement Gap Model: School Assessment and Accountability Sub-Sector."

15. See Appendix, "Model Figures," Figure 8, "Achievement Gap Model: School Parent Involvement Sub-Sector."

16. See Appendix, "Model Figures," Figure 9, "Achievement Gap Model: School Instructional Time Sub-Sector."

17. I should point out, however, that ultimately—as we think more deeply about the systemic implications of this analysis - it seems likely that we will think of policies that envision a wider view of the school sector. Such a view, for example, might well encompass incorporating school-led interventions in the home and community sectors into the policy model, interventions some of which are already part of the historical portfolio of efforts to close the achievement gaps.

18. It is important to recognize that, in some cases, stability is desirable, but that in other cases-sometimes called situations of "hyper-stability" or "ultra-stability"- the dynamics operate to block changes that are necessary for constructive adaptation to changing conditions. Discerning the difference is part of effective policy analysis.

19. See Appendix, "Model Figures," Figure 10, "The Teacher Expectations Feedback Loop in an Ineffective School."

20. See Appendix, "Model Figures," Figure 11, "The Teacher Expectations Feedback Loop in an Effective School."

21. See Appendix, "Model Figures," Figure 12, "A Negative Feedback Loop Around Tutoring and Support for Low-Performing Students."

22. See Appendix, "Model Figures," Figure 13, "The School-Focused School Achievement Model."

23. See Appendix, "Model Figures," Figure 14, "The Dynamics of School and Community Leadership."

24. See Appendix, "Model Figures," Figure 15, "The Dynamics of Extra Help."

25. See Appendix, "Model Figures," Figure 16, "The Dynamics of Teacher Quality."

26. There is an extensive list of additional factors - especially pre-natal and early childhood, including the effects of poverty on such things as nutrition, health care, and general stress - that influence brain development and lifetime vulnerability to negative health conditions (Paul, 2010; Dehaene, 2009; Rothstein, 2004)—which are distant from schooling and over which school personnel have essentially no control, are not included in this model.

27. You may notice that all of the arrows in this diagram are dashed arrows, which is unusual. Recall, though, that dashed arrows are used to show cross-sector effects, with the variable in the "other sector" displayed in a rectangular box instead of in a circle, which happens to be the case for all relationships in this sector. 